\title{
Melatonin added to freezing diluent improves canine (Bulldog) sperm cryosurvival
}

\author{
Julio A Martinez-Rodriguez, Francisco J Carbajal, Rocio Martinez-De-Anda, Alicia Alcantar-Rodriguez and \\ Alfredo Medrano \\ Multidisciplinary Research Unit (L2), Faculty of Superior Studies Cuautitlan, National Autonomous University of Mexico, Cuautitlan Izcalli, Mexico \\ Correspondence should be addressed to A Medrano; Email: amedrano@unam.mx
}

\begin{abstract}
Cryopreservation compromises the capacity of sperm fertilizing due to a series of alterations in the structure and physiology of the sperm. The use of antioxidants, such as melatonin, added to freezing media, may help to reduce sperm cryoinjury. To test the effect of melatonin on Bulldog (Canis lupus familiaris) sperm cryosurvival, spermatozoa were diluted in a standard freezing medium and cooled to $5^{\circ} \mathrm{C}$. Then, more freezing medium was added to obtain $200 \times 10^{6}$ cells $/ \mathrm{mL}$, and $5 \%$ glycerol. Diluted spermatozoa were treated with melatonin $(0.0,0.0005,0.002$, and $0.0035 \mathrm{~mol} / \mathrm{L})$, and packaged in $0.25 \mathrm{~mL}$ straws, which were further cooled to $-5^{\circ} \mathrm{C}$ before freezing in liquid nitrogen. Thawing was carried out at $70^{\circ} \mathrm{C}$ for $5 \mathrm{~s}$, and the progressive motility, viability, plasma membrane integrity, acrosome integrity, capacitation status, and plasma membrane fluidity of the spermatozoa $\left(\right.$ at $37^{\circ} \mathrm{C}$ ) were assessed. Data were analyzed using ANOVA to detect differences between the melatonin doses. There were statistical differences $(P<0.05)$ in the percentage of sperm having hyper-fluid membranes, intact acrosome, capacitated acrosome-intact, and acrosome-reacted. The values for the high melatonin doses $(0.002$ and $0.0035 \mathrm{~mol} / \mathrm{L}$ ) were better than for the low melatonin doses $(0.0$ and $0.0005 \mathrm{~mol} / \mathrm{L})$. In conclusion, 0.002 and $0.0035 \mathrm{~mol} / \mathrm{L}$ of melatonin improved the cryosurvival of sperm from male bulldogs.
\end{abstract}

\section{Lay summary}

Preservation of sperm by freezing enables breeding of individuals geographically separated; protocols for the dog may be used to preserve the semen from threatened wild canids. To improve fertility of female dogs that become pregnant with frozen and then defrosted sperm, these cells must survive that process which can be damaging whilst keeping their ability to fertilize. Antioxidants are substances capable of retarding or preventing the oxidation of any oxidizing substrate such as lipids, proteins, and DNA, which are structural compounds of the sperm. The use of antioxidants, added to freezing media, may provide the sperm the capacity to neutralize oxidative compounds, such as reactive oxygen species, produced during the freezing and thawing process. In this work we tested different levels of melatonin, a natural antioxidant, on dog (English Bulldog) sperm survival and quality after freezing. We found that adding melatonin to the freezing media improved sperm quality after thawing.

Key Words - Bulldog semen $\quad$ cryopreservation $\quad$ melatonin $>$ antioxidants Reproduction and Fertility (2020) 111-19

https://raf.bioscientifica.com

https://doi.org/10.1530/RAF-20-0022 (c) 2020 The authors Published by Bioscientifica Ltd

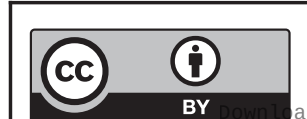

This work is licensed under a Creative Commons Attribution 4.0 International License. 


\section{Introduction}

Artificial insemination (AI) employing frozen-thawed spermatozoa represents a practical tool for dog breeding, especially for breeds such as the English Bulldog. Usually, males of this breed are unable to mate. Therefore, many litters are conceived by AI. Despite this, English bulldogs are a beloved breed in many countries, and their semen serves as a model to develop cryopreservation protocols for dog spermatozoa.

Freeze-thawing spermatozoa irreversibly impair the structure and function of the sperm (Watson 1995). During cryopreservation, the lipids that comprise the plasma membrane suffer the temperature-associated phenomenon known as a phase transition. As the temperature decreases, the lipids progressively change from a liquid-crystalline phase to a gel phase (Hazel 1995), and thus the plasma membrane becomes rigid. Most lipids undergo this change at temperatures above zero degrees (Watson 1995). However, there is evidence that some additional phase transitions could occur below zero degrees (Crowe et al. 1989). In addition, freezing affects the physical state of membrane lipids due to changes in the hydration level. The membrane phase transition may have different effects on the membrane conformational disorder in the frozen state when the ice nucleation occurs at different subzero temperatures (Balasubramanian et al. 2009).

Many approaches have been used to reduce cryodamage. We have tested the effect of different prefreeze cooling temperatures on boar (Garzon-Perez et al. 2010), horse (Contreras-Mendez \& Medrano 2016), and dog spermatozoa (Alcantar-Rodriguez \& Medrano 2017, Ortega-Morales et al. 2019). Another approach we have tested is the use of melatonin (MLT) as an antioxidant in cooling/freezing media for the conservation of ram (Cano-Suarez et al. 2013), goat buck (Moazzami et al. 2014), and boar spermatozoa (Martinez-Hernandez et al. 2018). MLT improved the quality of ram spermatozoa, but those of goat buck and boar spermatozoa were not affected. MLT has also been tested for the preservation of spermatozoa from several species such as humans, horses, bulls, and buffalos with varying results (for review see, Medrano et al. 2017). The protective role of MLT in sperm preservation is based on its antioxidant and antiapoptotic properties that may either maintain or improve sperm quality throughout that process (Reiter et al. 2007). It has been argued that the MLT action is targeted via the mitochondria by reducing oxygen consumption and, thus, reactive oxygen species (ROS) production
(Lopez et al. 2009). The actions of MLT on sperm functionality may be mediated by specific receptors such as $\mathrm{MT}_{1}$ and $\mathrm{MT}_{2}$, which have been identified in several animal species, including dogs (González-Arto et al. 2016).

However, the effectiveness of MLT seems to depend on the dose at which it is employed. Depending on the animal species, the best dose for improving the sperm quality and fertile capacity ranges from $0.00001 \mathrm{mM}$ to $0.003 \mathrm{~mol} / \mathrm{L}$ (for review see, Medrano et al. 2017). High doses of MLT may reduce the sperm fertilizing potential after cryopreservation. Since ROS production is excessively neutralized, oxidative phosphorylation may be inhibited, and consequently, the sperm motility and viability reduced (Souza et al. 2016).

These experimental approaches are directed to reduce the occurrence of severe changes in the plasma membrane fluidity (pre-freeze cooling to subzero temperatures) and oxidative stress (antioxidants) during cryopreservation. This study aimed to test the effect of pre-freeze cooling to $-5^{\circ} \mathrm{C}$ and MLT on dog sperm cryosurvival.

\section{Materials and methods}

All experiments complied with the Institutional Subcommittee for Care of Animals in Experimentation from the National Autonomous University of Mexico (Subcomité Institucional para el Cuidado de Animales en Experimentación, Universidad Nacional Autónoma de Mexico). This work was carried out at the Unit of Multidisciplinary Research, Laboratory of Animal Reproduction, from the National Autonomous University of Mexico (Faculty of Superior Studies Cuautitlan).

\section{Animals}

Ejaculates ( $n=8$, two from each male) from 4 English bulldogs (2-6 years old), collected throughout June 2017, were employed in a preliminary experiment. Ejaculates ( $n=24$, three from each male) from 8 English bulldogs (3-7 years old), collected from June to November 2018, were employed in the first experiment.

\section{Semen collection and assessment}

Semen was collected by digital stimulation (the whole ejaculate) once a week from each male. Immediately after collection, the semen was left for 30 min at approximately $23^{\circ} \mathrm{C}$ (room temperature) to adjust. Then, it was macroscopically assessed for volume, color, appearance,

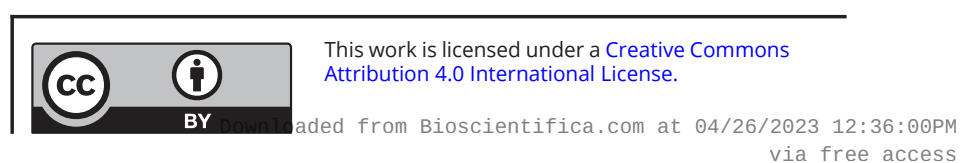


and presence of strange particles (blood, hair and pus). Immediately after centrifugation and resuspension in a standard freezing medium (see: semen processing), a small sample $(200 \mu \mathrm{L})$ of diluted spermatozoa was further diluted in phosphate-buffered solution (PBS; 1:5, v:v) at $37^{\circ} \mathrm{C}$ in a water bath, mixed, left for $10 \mathrm{~min}$ to equilibrate, and microscopically assessed. Only ejaculates showing at least $80 \%$ progressive motility and viability (SYBR14/PI) were included. The microscopic assessment was carried out as follows:

Progressive motility (percentage of cells showing forward movement) was subjectively assessed under light microscopy (Leica DMLS) using the $20 \times$ objective. A smear stained by eosin/nigrosine was employed to assess normal/abnormal spermatozoa (Barth \& Oko 1989) under light microscopy using the $100 \times$ objective, and 200 cells were counted for each determination.

The sperm plasma membrane integrity was assessed by fluorescent staining using SYBR14/propidium iodide (PI) (L7011 Invitrogen). Moreover, $50 \mu \mathrm{L}$ of diluted spermatozoa (in PBS $1+5, \mathrm{v} / \mathrm{v}$ ) was added to $5 \mu \mathrm{L}$ of SYBR14 (100 nmol/L) and mixed. Immediately after this, $5 \mu \mathrm{L}$ of PI $(12 \mu \mathrm{mol} / \mathrm{L})$ was added and mixed again for 10 s. Finally, $5 \mu \mathrm{L}$ of glutaraldehyde $(0.4 \%)$ was promptly added to immobilize the spermatozoa (Garner \& Johnson 1995). The percentage of live cells (green color: SYBR14positive and PI-negative) was calculated after counting 200 spermatozoa under fluorescence microscopy (Leica DMLS) using the $100 \times$ objective.

Acrosome integrity was assessed by fluorescent lectins. Diluted sperm were smeared on a slide and air-dried, and the cells were permeabilized in alcohol for $60 \mathrm{~min}$. Then, $50 \mu \mathrm{L}$ of PSA-FITC lectin (L0770; Sigma) was spread on a slide that was left in the dark for $10 \mathrm{~min}$. Immediately after, the slide was gently washed with distilled water and air-dried (Medrano et al. 2009). One drop of an antifade solution (DABCO $0.220 \mathrm{~mol} / \mathrm{L}$ in glycerol/PBS, D-2522; Sigma) was placed on the slide, and a coverslip was positioned on top. The percentage of cells showing a smooth and well-defined acrosome was calculated after counting 200 spermatozoa under fluorescence microscopy using the $100 \times$ objective.

Sperm capacitation status was assessed using the chlortetracycline (CTC) assay as follows: $100 \mu \mathrm{L}$ of diluted sperm (in PBS $1+5, \mathrm{v} / \mathrm{v}$ ) was added to $100 \mu \mathrm{L}$ of CTC solution ( $\mathrm{pH} 7.8)$, mixed for $30 \mathrm{~s}$, and $20 \mu \mathrm{L}$ of glutaraldehyde $(0.2 \%)$ was added to immobilize the sperm (Green \& Watson 2001). CTC-stained sperm were mixed $(1: 1, v / v)$ with an antifade solution on a slide, and a coverslip was positioned on top. The percentage of cells showing any of the CTC patterns: F, with uniform fluorescence over the whole head (non-capacitated acrosome-intact spermatozoa); B, with a fluorescencefree band in the post-acrosomal region (capacitated acrosome-intact spermatozoa), or AR, with almost no fluorescence over the whole head except for a band of fluorescence in the equatorial segment (acrosomereacted spermatozoa), were calculated after counting 200 spermatozoa under fluorescence microscopy using the $100 \times$ objective.

To assess the sperm plasma membrane fluidity, a merocyanine 540 assay was carried out as follows: a stock solution of merocyanine $(0.005 \mathrm{~mol} / \mathrm{L})$ in dimethyl sulfoxide (DMSO; 154938; Sigma) was prepared and stored at room temperature $\left(23^{\circ} \mathrm{C}\right)$, protected from light until use. Then, a work solution of merocyanine $(0.000004 \mathrm{~mol} / \mathrm{L})$ in PBS $(495 \mu \mathrm{L} \mathrm{PBS}+5 \mu \mathrm{L}$ merocyanine $(0.005 \mathrm{~mol} / \mathrm{L})$ in DMSO) was freshly prepared (Harrison et al. 1996). Afterwards, $140 \mu \mathrm{L}$ of sperm in PBS was added to $10 \mu \mathrm{L}$ of the merocyanine working solution, mixed, and left for $1 \mathrm{~min}$ to interact. Then, $22 \mu \mathrm{L}$ of glutaraldehyde $(0.4 \%)$ was added to fix the sperm. One drop of this mix and one drop of the antifade solution (DABCO $0.220 \mathrm{~mol} / \mathrm{L}$ in glycerol/PBS) were placed on a warm glass slide, and a glass cover slide was positioned on top. Gentle pressure was applied over the cover slide, with the aid of absorbent paper to eliminate the excess liquid. The percentage of cells showing either of the merocyanine patterns: opaque (low fluidity) or brilliant (high fluidity-high-binding cells) were calculated after counting 200 spermatozoa under fluorescence microscopy (Leica DMLS) using the $100 \times$ objective.

Not all variables were measured for all experiments. However, each stage indicates which of them were assessed.

\section{Semen processing}

The semen was centrifuged at $750 \boldsymbol{g}$ for $10 \mathrm{~min}$, the supernatant was removed, and the cell pellet was resuspended with an egg yolk/tris-based freezing medium (EYT) containing 3\% glycerol (v/v) (Peña \& Linde Forsberg 2000) to obtain a concentration of $400 \times 10^{6}$ cells $/ \mathrm{mL}$. These procedures were performed at about $23^{\circ} \mathrm{C}$ (room temperature). The sperm concentration was estimated from a 1:200 dilution (semen: formaldehyde saline solution, $v / v$ ) with the aid of a Neubauer chamber using the $40 \mathrm{x}$ objective. 


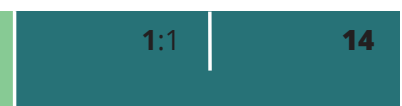

\section{Cooling and freezing of spermatozoa}

Sperm diluted in EYT (3\% glycerol) were cooled from room temperature to $5^{\circ} \mathrm{C}$ for approximately $2 \mathrm{~h}$ $\left(0.15^{\circ} \mathrm{C} / \mathrm{min}\right)$. Then, EYT medium containing $7 \%$ glycerol $(\mathrm{v} / \mathrm{v})$ was slowly added in three equal parts with $10 \mathrm{~min}$ periods between each to obtain a final concentration of $200 \times 10^{6}$ cells $/ \mathrm{mL}$ and 5\% glycerol. Then, the diluted spermatozoa were divided into aliquots and MLT was added as follows:

Preliminary experiment: (i) 0.0, (ii) 0.001, and (iii) $0.002 \mathrm{~mol} / \mathrm{L}$

First experiment: (i) 0.0, (ii) 0.0005, (iii) 0.002, and (iv) $0.0035 \mathrm{~mol} / \mathrm{L}$

A mix of DMSO + PBS $(1+9, \mathrm{v} / \mathrm{v})$ was added to the control group (i.e. $0.0 \mathrm{~mol} / \mathrm{L}$ of $\mathrm{MLT}$ ) so that all treatments contained the same amount of DMSO (used to dissolve MLT). Then, the diluted spermatozoa were packaged in $0.5 \mathrm{~mL}$ (preliminary experiment) or $0.25 \mathrm{~mL}$ (first experiment) plastic straws, which were sealed with polyvinyl alcohol. The straws were placed in a special recipient containing a saline solution $(\mathrm{NaCl} 10 \%$, $\mathrm{w} / \mathrm{v})$ at $5^{\circ} \mathrm{C}$. Each straw was positioned inside a plastic cylinder with a diameter slightly larger than the straw. One end of these cylinders was sealed and fixed to the bottom of the recipient using plasticine, while the other end was opened and stood above water (Fig. 1). In this way, the straws were maintained in a vertical position, separated from each other, and dried. The straws were further cooled to $-5^{\circ} \mathrm{C}\left(0.12^{\circ} \mathrm{C} / \mathrm{min}\right)$ by immersing the special recipient in crushed saline ice $(\mathrm{NaCl} 10 \%, \mathrm{w} / \mathrm{v})$ at $-12^{\circ} \mathrm{C}$. This method has been previously validated in our laboratory (Alcantar-Rodriguez \& Medrano 2017). The temperature was monitored with the aid of a thermocouple (HANNA Instruments, USA) positioned inside a straw containing EYT (5\% glycerol). When the straw reached $-5^{\circ} \mathrm{C}$, they were exposed to nitrogen vapors, $4 \mathrm{~cm}$ above liquid nitrogen for $15 \mathrm{~min}$, and then immersed in liquid nitrogen and stored in a Dewar until required.

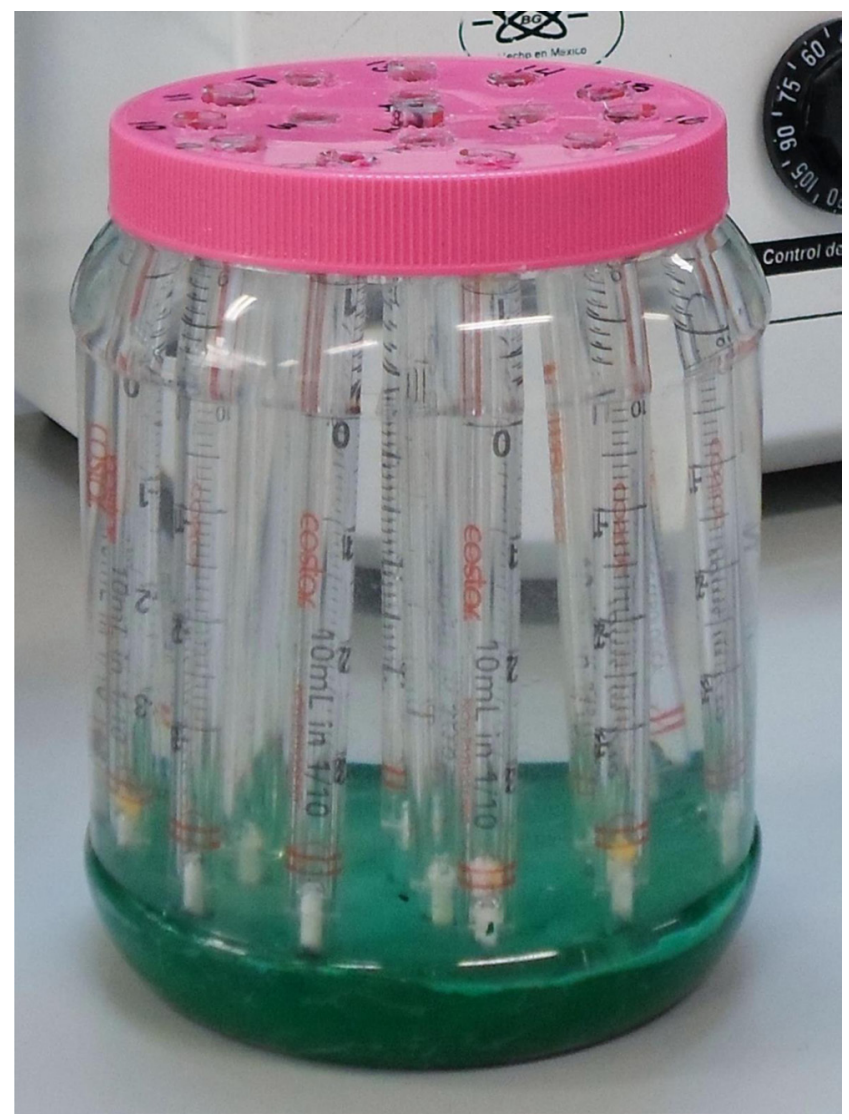

Figure 1 The special recipient containing saline solution $(\mathrm{NaCl} 10 \%, \mathrm{w} / \mathrm{v})$ employed to cool the straws from $5^{\circ} \mathrm{C}$ to $-5^{\circ} \mathrm{C}$; each straw $(n=16)$ was inserted inside one of the plastic cylinders.

\section{Thawing of spermatozoa}

The straws (12 per ejaculate, three per treatment) were thawed at $37^{\circ} \mathrm{C}$ for $30 \mathrm{~s}$ (preliminary experiment) or $70^{\circ} \mathrm{C}$ for $5 \mathrm{~s}$ (first experiment) in a water bath. The content was immediately poured into dry tubes located in another water bath at $37^{\circ} \mathrm{C}$. After $10 \mathrm{~min}$, the sperm were assessed as described previously.

\section{Experimental design}

To assess the effect of MLT on the gross measures of sperm quality, a preliminary experiment was carried out to test

Table 1 Effect of cooling to different target temperatures on English Bulldog sperm cryosurvival. Values are presented as means \pm S.E.M.

\begin{tabular}{lccc} 
Pre-freeze cooling & Progressive motility $(\%)$ & $\begin{array}{c}\text { Plasma membrane } \\
\text { integrity }(\%)\end{array}$ \\
\cline { 1 - 1 }$-5^{\circ} \mathrm{C}$ & $24.9 \pm 3.34$ & & $28.3 \pm 2.48$ \\
$-5^{\circ} \mathrm{C}$ & $22.7 \pm 3.25$ & & $33.2 \pm 2.67$ \\
\hline
\end{tabular}

\begin{tabular}{|c|c|c|c|}
\hline \multicolumn{3}{|c|}{ Capacitation status (CTC patterns) } & \multirow[b]{2}{*}{ Acrosome integrity (\%) } \\
\hline $\mathrm{F}(\%)$ & $\mathrm{B}(\%)$ & AR (\%) & \\
\hline $17.9 \pm 3.50 a$ & $69.9 \pm 2.53 a$ & $12.0 \pm 1.59$ & $58.9 \pm 5.56 a$ \\
\hline $30.8 \pm 6.32 b$ & $59.4 \pm 4.71 b$ & $10.0 \pm 2.15$ & $72.8 \pm 4.29 b$ \\
\hline
\end{tabular}

Different letters in columns indicate significant differences $(P<0.05)$.

https://raf.bioscientifica.com

https://doi.org/10.1530/RAF-20-0022 (c) 2020 The authors Published by Bioscientifica Ltd

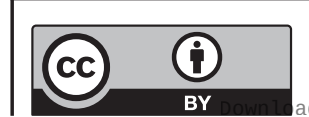

This work is licensed under a Creative Commons Attribution 4.0 International License. 
Table 2 Effect of cooling to different target temperatures and melatonin (MLT) on English Bulldog sperm cryosurvival. Values are presented as means \pm S.E.M.

\begin{tabular}{|c|c|c|c|c|c|c|}
\hline \multirow[b]{2}{*}{ Pre-freeze cooling/MLT } & \multirow{2}{*}{$\begin{array}{l}\text { Progressive } \\
\text { motility (\%) }\end{array}$} & \multirow{2}{*}{$\begin{array}{c}\text { Plasma membrane } \\
\text { integrity }(\%)\end{array}$} & \multicolumn{3}{|c|}{ Capacitation status (CTC patterns) } & \multirow[b]{2}{*}{ Acrosome integrity (\%) } \\
\hline & & & $\mathrm{F}(\%)$ & $\mathrm{B}(\%)$ & AR (\%) & \\
\hline \multicolumn{7}{|l|}{$+5^{\circ} \mathrm{C}$} \\
\hline 0 & $26.4 \pm 8.48$ & $24.6 \pm 5.86$ & $20.7 \pm 11.05$ & $71.8 \pm 9.71$ & $7.5 \pm 3.88$ & $75.5 \pm 2.50$ \\
\hline 1 & $22.0 \pm 7.02$ & $35.7 \pm 5.15$ & $21.8 \pm 7.99$ & $69.5 \pm 5.63$ & $8.7 \pm 2.40$ & $50.3 \pm 25.25$ \\
\hline 2 & $24.8 \pm 6.59$ & $21.9 \pm 2.38$ & $25.3 \pm 12.05$ & $64.0 \pm 7.57$ & $9.7 \pm 4.28$ & $64.7 \pm 19.91$ \\
\hline \multicolumn{7}{|l|}{$-5^{\circ} \mathrm{C}$} \\
\hline 0 & $24.8 \pm 7.40$ & $40.7 \pm 4.44$ & $43.2 \pm 18.39$ & $50.8 \pm 14.13$ & $6.0 \pm 4.54$ & $88.0 \pm 7.00$ \\
\hline 1 & $19.0 \pm 6.03$ & $31.7 \pm 4.78$ & $49.0 \pm 16.00$ & $47.3 \pm 15.25$ & $3.8 \pm 0.75$ & $82.3 \pm 11.75$ \\
\hline 2 & $17.5 \pm 5.88$ & $31.1 \pm 6.20$ & $42.3 \pm 19.75$ & $56.3 \pm 18.75$ & $1.5 \pm 1.00$ & $82.3 \pm 5.33$ \\
\hline
\end{tabular}

There were no differences between treatments (cooling x melatonin). MLT: $0,0.0 ; 1,0.001 ; 2,0.002 \mathrm{~mol} / \mathrm{L}$.

the effect of 0.0, 0.001, and $0.002 \mathrm{~mol} / \mathrm{L}$ of MLT on the cryosurvival of spermatozoa from English bulldogs (four males (replicates), two ejaculates per male). The semen was collected at the laboratory, assessed, and processed as previously mentioned. Each ejaculate was processed separately and subjected to all the treatments (aliquots). The diluted spermatozoa were cooled to either $+5^{\circ} \mathrm{C}$ or $-5^{\circ} \mathrm{C}$, and frozen-thawed as previously mentioned. The progressive motility, plasma membrane integrity, capacitation status, and acrosome integrity were assessed before and after cryopreservation. This experiment was replicated four times.

In the first experiment, the effects of $0.0,0.0005$, 0.0020 , and $0.0035 \mathrm{~mol} / \mathrm{L}$ of MLT were tested on the cryosurvival of spermatozoa from English bulldogs (eight males (replicates), three ejaculates per male). The semen was collected at the laboratory, assessed, and processed as mentioned. Each ejaculate was processed separately and subjected to all treatments (aliquots). The diluted

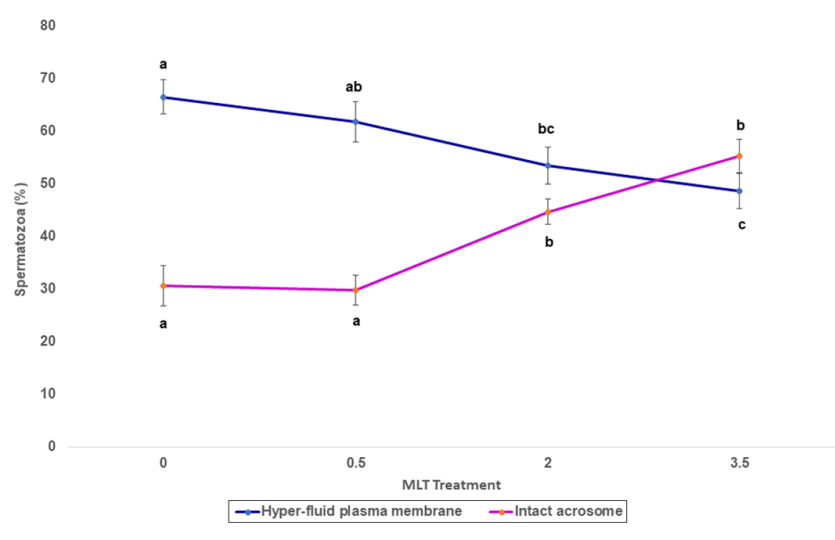

Figure 2 Hyper-fluid plasma membranes (\%) and intact acrosomes (\%) for each for each of the treatments of melatonin (MLT). 0, 0.0; 0.5, 0.0005; 2 , $0.002 ; 3.5,0.0035 \mathrm{~mol} / \mathrm{L}$. Values are means \pm S.E.M. Different letters within each line indicate significant differences $(P<0.05)$. spermatozoa were cooled to $-5^{\circ} \mathrm{C}$, and freeze-thawed as previously mentioned.

The progressive motility, plasma membrane integrity, plasma membrane fluidity, capacitation status, and acrosome integrity were assessed before and after cryopreservation. This experiment was replicated eight times.

\section{Statistical analysis}

Sperm quality data from the fresh semen were analyzed using descriptive statistics only. Data regarding the sperm quality from the cooling treatments of the preliminary experiment (i.e. $+5 \mathrm{vs}-5^{\circ} \mathrm{C}$ ) were analyzed using the paired $\mathrm{T}$ test; data from the MLT treatments and individual dogs were pooled for each cooling temperature. For the ANOVA of cooling temperatures $\mathrm{x}$ MLT doses, an individual dog was a fixed effect. The sperm quality data from the (i) cooling temperatures $\times$ MLT treatments (preliminary experiment), and (ii) MLT treatments (first experiment) were arcsine transformed to normalize the data before the ANOVA (Snedecor \& Cochran 1989). The general linear model procedure from SPSS version 15.0 (2006) was used in the analysis. Effects included in the model of the first experiment were the treatments $(0.0,0.0005,0.0020$, $0.0035 \mathrm{~mol} / \mathrm{L} \mathrm{MLT}$ ), and interaction $\operatorname{dog} \times$ treatment. Results were expressed as mean \pm s.E.M. Values were considered to be significant at $P<0.05$.

\section{Results}

In the preliminary experiment, there were significant differences $(P<0.05)$ between the cooling temperatures in the percentages of non-capacitated, acrosome-intact spermatozoa (Pattern F, CTC assay): $17.9 \pm 3.50 \%\left(+5^{\circ} \mathrm{C}\right)$ vs $30.8 \pm 6.32 \%\left(-5^{\circ} \mathrm{C}\right)$; capacitated, acrosome-intact

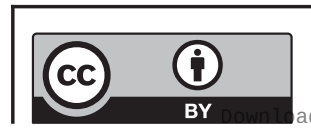

This work is licensed under a Creative Commons Attribution 4.0 International License. 
Table 3 Effect of melatonin (MLT) on English Bulldog sperm cryosurvival. Values are presented as means \pm S.E.M.

\begin{tabular}{|c|c|c|c|}
\hline MLT & $\begin{array}{l}\text { Progressive } \\
\text { motility (\%) }\end{array}$ & $\begin{array}{c}\text { Plasma membrane } \\
\text { integrity (\%) }\end{array}$ & $\begin{array}{l}\text { Hyper-fluid plasma } \\
\text { membrane (\%) }\end{array}$ \\
\hline 0 & $42.7 \pm 4.63$ & $33.2 \pm 3.42$ & $66.5 \pm 3.20 a$ \\
\hline 0.5 & $36.5 \pm 4.56$ & $36.1 \pm 3.52$ & $61.8 \pm 3.84 a b$ \\
\hline 2.0 & $41.3 \pm 4.21$ & $42.1 \pm 2.81$ & $53.4 \pm 3.53 b c$ \\
\hline 3.5 & $45.1 \pm 4.15$ & $42.4 \pm 2.85$ & $48.6 \pm 3.33 c$ \\
\hline
\end{tabular}

\begin{tabular}{|c|c|c|}
\hline \multicolumn{3}{|c|}{ Capacitation status (CTC patterns) } \\
\hline $\mathrm{F}(\%)$ & $\mathrm{B}(\%)$ & AR (\%) \\
\hline $21.9 \pm 2.23$ & $34.4 \pm 2.29 a$ & $45.6 \pm 2.88 a$ \\
\hline $22.9 \pm 1.55$ & $40.4 \pm 1.83 a$ & $36.8 \pm 2.41 a$ \\
\hline $21.8 \pm 1.24$ & $51.3 \pm 2.35 b$ & $26.2 \pm 2.43 b$ \\
\hline $21.7 \pm 1.65$ & $52.9 \pm 2.45 b$ & $26.1 \pm 2.64 b$ \\
\hline
\end{tabular}

\begin{tabular}{c}
$\begin{array}{c}\text { Acrosome } \\
\text { integrity (\%) }\end{array}$ \\
\hline $30.6 \pm 3.81 \mathrm{a}$ \\
$29.8 \pm 2.84 \mathrm{a}$ \\
$44.7 \pm 2.43 \mathrm{~b}$ \\
$55.2 \pm 3.16 \mathrm{~b}$ \\
\hline
\end{tabular}

Values are means \pm S.E.M. Different letters in columns indicate significant differences $(P<0.05)$. MLT: $0,0.0 ; 0.5,0.0005 ; 2,0.002 ; 3.5,0.0035$ mol/L.

spermatozoa (Pattern B, CTC assay): $69.9 \pm 2.53 \%\left(+5^{\circ} \mathrm{C}\right)$ vs $59.4 \pm 4.71 \%\left(-5^{\circ}\right)$; and acrosome-intact spermatozoa (PSA-FITC lectin): $58.9 \pm 5.56 \%\left(+5^{\circ} \mathrm{C}\right)$ vs $72.8 \pm 4.29 \%$ $\left(-5^{\circ} \mathrm{C}\right.$; Table 1$)$. In contrast, there were no significant differences in any of the assessed variables between the MLT doses or between cooling and MLT (Table 2).

In the first experiment, there were significant differences $(P<0.05)$ in the percentages of sperm with hyper-fluid membranes (MC540 brilliant pattern) between the 0.0 and either 0.002 or $0.0035 \mathrm{~mol} / \mathrm{L}$ of MLT (Fig. 2).

In addition, there were significant differences $(P<0.05)$ in the percentages of sperm with intact acrosomes between the low $(0.0$ and $0.0005 \mathrm{~mol} / \mathrm{L})$ and high $(0.002$ and $0.0035 \mathrm{~mol} / \mathrm{L})$ MLT treatments. The values of the high MLT doses were higher than those of the low MLT treatments (Fig. 2).

There were significant differences $(P<0.05)$ in the percentages of capacitated acrosome-intact spermatozoa (Pattern B, CTC assay) between the low and high MLT treatments. There were also significant differences $(P<0.05)$ in the percentages of acrosome-reacted spermatozoa (Pattern AR, CTC assay) between the low and high MLT treatments (Table 3).

There were significant differences $(P<0.05)$ between some dogs (regardless of MLT treatment) in sperm motility: male 1 had the highest $(61.5 \pm 4.12 \%)$ and males 4,6 , and 8 the smallest $(33.5 \pm 6.04 \%, 35.8 \pm 7.04 \%$, $26.5 \pm 3.63 \%$, respectively). Also, there were significant differences $(P<0.05)$ in sperm plasma membrane integrity: males 1 and 2 displayed the highest $(50.2 \pm 5.07 \%$ and $44.9 \pm 5.61 \%$, respectively) and male 8 the smallest $(24.6 \pm 4.37 \%)$ percentages (Table 4$)$.

Regarding differences in sperm quality due to MLT treatments in the same dog, sperm from some males had higher (acrosome integrity, capacitated acrosome-intact) or smaller (plasma membrane hyper-fluidity, acrosomereacted) values in some variables when high levels of MLT were added (Table 5). In contrast, the sperm quality from other males was independent of MLT treatments.

\section{Discussion}

In the preliminary experiment, the effects of MLT $(0.0,0.001$, and $0.002 \mathrm{~mol} / \mathrm{L})$ and pre-freeze cooling to $-5^{\circ} \mathrm{C}$ were tested on the cryosurvival of sperm from male English bulldogs. MLT produced no differences in sperm cryosurvival. However, pre-freeze cooling to $-5^{\circ} \mathrm{C}$ improved some sperm attributes. In a similar study, using a different breed of dogs (Belgian and German Shepherds), cooling reduced the percentage of hyper-fluid membranes in comparison to the usual cooling to $+5^{\circ} \mathrm{C}$ (Ortega-Morales et al. 2019). These observations support the proposed hypothesis that the cooling of spermatozoa to subzero temperatures favors sperm plasma membrane reorganization after the lipid phase transition takes place,

Table 4 Sperm cryosurvival from different English Bulldog males regardless MLT treatments. Values are presented as

means \pm S.E.M.

\begin{tabular}{|c|c|c|c|}
\hline Male & $\begin{array}{l}\text { Progressive } \\
\text { motility (\%) }\end{array}$ & $\begin{array}{c}\text { Plasma membrane } \\
\text { integrity }(\%)\end{array}$ & $\begin{array}{l}\text { Hyper-fluid plasma } \\
\text { membrane (\%) }\end{array}$ \\
\hline 1 & $61.5 \pm 4.12 a$ & $50.2 \pm 5.07 a$ & $59.7 \pm 5.79$ \\
\hline 2 & $44.5 \pm 7.61 \mathrm{ab}$ & $44.9 \pm 5.61 a$ & $54.1 \pm 4.00$ \\
\hline 3 & $36.6 \pm 5.55 a b$ & $38.9 \pm 4.41 a b$ & $57.7 \pm 5.95$ \\
\hline 4 & $33.5 \pm 6.04 b c$ & $34.8 \pm 3.73 a b$ & $53.3 \pm 7.70$ \\
\hline 5 & $47.1 \pm 4.86 a b c$ & $39.5 \pm 3.87 a b$ & $61.0 \pm 5.07$ \\
\hline 6 & $35.8 \pm 7.04 \mathrm{bc}$ & $39.7 \pm 2.78 a b$ & $63.6 \pm 3.45$ \\
\hline 7 & $45.8 \pm 5.31 \mathrm{ac}$ & $35.1 \pm 3.26 a b$ & $45.3 \pm 5.06$ \\
\hline 8 & $26.5 \pm 3.63 b c$ & $24.6 \pm 4.37 b$ & $66.0 \pm 1.91$ \\
\hline
\end{tabular}

Different letters in columns indicate significant differences $(P<0.05)$.
Acrosome integrity (\%)

$36.1 \pm 5.44$

$32.5 \pm 4.92$

$44.1 \pm 3.76$

$39.5 \pm 5.30$

$44.0 \pm 5.33$

$28.8 \pm 5.30$

$45.4 \pm 6.18$

$50.1 \pm 4.23$ 
Table 5 Characteristics of frozen-thawed spermatozoa from eight individual Bulldog males under the effect of melatonin (MLT). Values are presented as means \pm S.E.M.

\begin{tabular}{|c|c|c|c|c|c|c|c|}
\hline \multirow{2}{*}{$\begin{array}{l}\text { Dogs/MLT } \\
\text { treatment }\end{array}$} & \multirow{2}{*}{$\begin{array}{l}\text { Progressive } \\
\text { motility (\%) }\end{array}$} & \multirow[b]{2}{*}{ Viability (\%) } & \multirow{2}{*}{$\begin{array}{c}\text { Hyperfluid } \\
\text { membranes (\%) }\end{array}$} & \multirow{2}{*}{$\begin{array}{c}\text { Intact } \\
\text { acrosomes (\%) }\end{array}$} & \multicolumn{3}{|c|}{ Capacitation status (\%) } \\
\hline & & & & & $\mathrm{F}$ & $\mathrm{B}$ & $A R$ \\
\hline \multicolumn{8}{|l|}{ Male 1} \\
\hline 0.0 & $68.3 \pm 4.4$ & $40.0 \pm 10.4$ & $72.8 \pm 4.6$ & $19.0 \pm 3.2 a$ & $21.3 \pm 7.0$ & $38.7 \pm 9.4$ & $40.0 \pm 11.6$ \\
\hline 0.5 & $61.0 \pm 10.7$ & $49.0 \pm 13.7$ & $68.7 \pm 10.0$ & $22.7 \pm 6.7 a b$ & $21.3 \pm 4.7$ & $44.0 \pm 2.3$ & $34.7 \pm 3.7$ \\
\hline 2.0 & $51.7 \pm 10.1$ & $56.2 \pm 12.6$ & $52.5 \pm 13.8$ & $43.0 \pm 5.6 b c$ & $25.7 \pm 2.3$ & $52.7 \pm 4.1$ & $15.7 \pm 1.2$ \\
\hline 3.5 & $65.0 \pm 7.6$ & $55.5 \pm 6.3$ & $44.7 \pm 12.7$ & $59.7 \pm 5.1 \mathrm{c}$ & $17.0 \pm 3.2$ & $56.0 \pm 5.6$ & $27.0 \pm 8.5$ \\
\hline \multicolumn{8}{|l|}{ Male 2} \\
\hline 0.0 & $39.0 \pm 19.3$ & $41.5 \pm 14.0$ & $62.3 \pm 6.7$ & $19.5 \pm 4.0$ & $17.3 \pm 2.9$ & $31.0 \pm 2.7 a$ & $51.7 \pm 2.2 a$ \\
\hline 0.5 & $38.3 \pm 19.8$ & $41.5 \pm 20.1$ & $58.7 \pm 13.0$ & $23.2 \pm 4.5$ & $28.0 \pm 3.6$ & $35.0 \pm 2.9 a$ & $37.0 \pm 2.5 b$ \\
\hline 2.0 & $49.0 \pm 15.4$ & $51.8 \pm 4.8$ & $50.5 \pm 5.8$ & $41.8 \pm 7.1$ & $25.3 \pm 1.9$ & $57.7 \pm 2.2 b$ & $20.3 \pm 2.3 c$ \\
\hline 3.5 & $51.7 \pm 14.3$ & $44.8 \pm 5.8$ & $45.0 \pm 3.6$ & $45.5 \pm 13.8$ & $19.7 \pm 0.3$ & $58.3 \pm 2.9 b$ & $22.0 \pm 3.1 c$ \\
\hline \multicolumn{8}{|l|}{ Male 3} \\
\hline 0.0 & $42.3 \pm 13.8$ & $24.2 \pm 7.7$ & $67.0 \pm 11.9$ & $31.8 \pm 3.2 \mathrm{a}$ & $25.7 \pm 12.7$ & $39.3 \pm 5.6 a$ & $50.3 \pm 7.5 a$ \\
\hline 0.5 & $27.3 \pm 8.2$ & $36.8 \pm 6.7$ & $69.3 \pm 12.1$ & $34.2 \pm 2.8 a$ & $22.7 \pm 4.7$ & $40.3 \pm 5.5 a$ & $37.0 \pm 9.1 \mathrm{ab}$ \\
\hline 2.0 & $33.3 \pm 8.8$ & $44.0 \pm 8.9$ & $49.8 \pm 11.1$ & $50.8 \pm 3.9 b$ & $22.7 \pm 3.2$ & $54.0 \pm 2.1 \mathrm{ab}$ & $23.3 \pm 4.1 b$ \\
\hline 3.5 & $43.3 \pm 15.9$ & $50.5 \pm 7.3$ & $44.7 \pm 11.8$ & $59.5 \pm 3.3 b$ & $21.3 \pm 3.2$ & $59.3 \pm 3.5 b$ & $19.3 \pm 0.9 b$ \\
\hline \multicolumn{8}{|l|}{ Male 4} \\
\hline 0.0 & $27.0 \pm 10.5$ & $22.7 \pm 8.2$ & $52.3 \pm 19.5$ & $27.8 \pm 9.1$ & $25.0 \pm 7.9$ & $39.0 \pm 8.0$ & $36.0 \pm 6.1$ \\
\hline 0.5 & $35.3 \pm 21.5$ & $37.5 \pm 7.5$ & $52.3 \pm 19.2$ & $28.7 \pm 8.1$ & $27.0 \pm 4.6$ & $41.7 \pm 7.3$ & $30.7 \pm 10.3$ \\
\hline 2.0 & $35.0 \pm 12.6$ & $34.0 \pm 4.0$ & $53.3 \pm 19.4$ & $48.0 \pm 11.0$ & $20.0 \pm 1.5$ & $52.3 \pm 3.9$ & $27.7 \pm 2.9$ \\
\hline 3.5 & $36.7 \pm 6.7$ & $44.8 \pm 6.1$ & $55.0 \pm 12.2$ & $53.7 \pm 9.4$ & $24.3 \pm 1.2$ & $54.0 \pm 6.9$ & $21.7 \pm 5.8$ \\
\hline \multicolumn{8}{|l|}{ Male 5} \\
\hline 0.0 & $48.0 \pm 11.1$ & $43.8 \pm 10.6$ & $73.5 \pm 4.4$ & $36.2 \pm 11.3$ & $25.7 \pm 5.6$ & $28.3 \pm 4.6 a$ & $46.0 \pm 4.2 a$ \\
\hline 0.5 & $38.3 \pm 8.8$ & $27.2 \pm 2.4$ & $68.2 \pm 3.4$ & $32.2 \pm 9.2$ & $30.3 \pm 5.4$ & $41.7 \pm 4.4 a b$ & $28.0 \pm 5.9 a b$ \\
\hline 2.0 & $47.3 \pm 13.2$ & $39.5 \pm 8.5$ & $54.8 \pm 13.8$ & $42.8 \pm 7.8$ & $17.7 \pm 1.5$ & $60.0 \pm 3.5 b$ & $22.3 \pm 2.9 b$ \\
\hline 3.5 & $54.7 \pm 8.7$ & $47.7 \pm 4.3$ & $47.5 \pm 11.5$ & $64.7 \pm 6.1$ & $24.0 \pm 4.6$ & $56.0 \pm 5.0 b$ & $20.0 \pm 5.1 b$ \\
\hline \multicolumn{8}{|l|}{ Male 6} \\
\hline 0.0 & $41.0 \pm 18.6$ & $39.2 \pm 2.7$ & $75.8 \pm 3.6 a$ & $21.3 \pm 10.9$ & $19.7 \pm 6.8$ & $32.0 \pm 5.1$ & $48.3 \pm 11.7$ \\
\hline 0.5 & $31.0 \pm 9.7$ & $47.3 \pm 7.4$ & $67.2 \pm 5.2 \mathrm{ab}$ & $21.3 \pm 9.1$ & $14.7 \pm 0.9$ & $39.3 \pm 4.8$ & $47.7 \pm 5.0$ \\
\hline 2.0 & $43.0 \pm 22.1$ & $39.7 \pm 5.2$ & $60.8 \pm 5.7 a b$ & $34.0 \pm 9.5$ & $23.0 \pm 7.4$ & $39.3 \pm 10.1$ & $34.3 \pm 12.9$ \\
\hline 3.5 & $28.0 \pm 9.1$ & $32.7 \pm 5.2$ & $50.7 \pm 4.5 b$ & $38.3 \pm 14.6$ & $24.7 \pm 8.7$ & $36.7 \pm 8.8$ & $44.3 \pm 14.8$ \\
\hline \multicolumn{8}{|l|}{ Male 7} \\
\hline 0.0 & $45.0 \pm 9.0$ & $33.0 \pm 2.3$ & $60.5 \pm 9.8$ & $36.0 \pm 19.3$ & $25.3 \pm 5.3$ & $37.3 \pm 1.3$ & $37.3 \pm 4.8$ \\
\hline 0.5 & $39.3 \pm 14.6$ & $33.2 \pm 1.0$ & $41.3 \pm 12.1$ & $38.5 \pm 14.5$ & $20.7 \pm 4.3$ & $45.3 \pm 7.4$ & $34.0 \pm 6.7$ \\
\hline 2.0 & $45.7 \pm 8.1$ & $39.7 \pm 6.1$ & $41.5 \pm 6.0$ & $44.5 \pm 5.8$ & $23.7 \pm 3.2$ & $43.3 \pm 8.8$ & $33.0 \pm 9.1$ \\
\hline 3.5 & $53.3 \pm 14.5$ & $34.5 \pm 13.3$ & $38.0 \pm 11.3$ & $62.7 \pm 2.4$ & $24.3 \pm 7.9$ & $49.3 \pm 4.7$ & $26.3 \pm 3.2$ \\
\hline \multicolumn{8}{|l|}{ Male 8} \\
\hline 0.0 & $31.0 \pm 13.6$ & $21.2 \pm 14.8$ & $67.8 \pm 3.1$ & $53.2 \pm 11.6$ & $15.3 \pm 3.7$ & $29.7 \pm 12.9$ & $55.0 \pm 13.5$ \\
\hline 0.5 & $21.7 \pm 4.4$ & $16.7 \pm 2.2$ & $69.0 \pm 4.3$ & $37.7 \pm 7.8$ & $18.7 \pm 0.9$ & $36.0 \pm 8.3$ & $45.3 \pm 7.9$ \\
\hline 2.0 & $25.0 \pm 5.0$ & $31.8 \pm 8.4$ & $63.5 \pm 1.3$ & $52.3 \pm 4.9$ & $16.7 \pm 3.8$ & $50.7 \pm 10.4$ & $32.7 \pm 9.6$ \\
\hline 3.5 & $28.3 \pm 6.0$ & $28.8 \pm 7.4$ & $63.5 \pm 6.2$ & $57.3 \pm 7.9$ & $18.0 \pm 6.0$ & $53.7 \pm 12.0$ & $28.3 \pm 6.4$ \\
\hline
\end{tabular}

Different letters within males indicate significant differences $(P<0.05)$. MLT: $0,0.0 ; 0.5,0.0005 ; 2,0.002 ; 3.5,0.0035 \mathrm{~mol} / \mathrm{L}$.

thus avoiding an excessive increase in membrane fluidity (Watson 1995, Holt 2000). Balasubramanian et al. (2009) reported that ice nucleation at $-6^{\circ} \mathrm{C}$ enables a fraction of cellular and membrane-bound water to stay in the cell and therefore promotes cell viability.

In the first experiment, different doses of MLT were tested on the cryosurvival of sperm from male English bulldogs. In general, sperm cryosurvival was significantly better with high $(0.002$ and $0.0035 \mathrm{~mol} / \mathrm{L})$ than low $(0.0$ and $0.0005 \mathrm{~mol} / \mathrm{L}$ ) doses of MLT. In this experiment, some modifications to the freeze-thawing protocol (i.e. packaging in $0.25 \mathrm{~mL}$ straws instead of $0.5 \mathrm{~mL}$, thawing at $70^{\circ} \mathrm{C}$ instead of $37^{\circ} \mathrm{C}$ ) were introduced in addition to the different doses of MLT.

Regarding changes in plasma membrane fluidity before and after cryopreservation, the values of hyperfluid membranes obtained in this work $(16.1 \%$ vs $57.6 \%$, fresh vs frozen-thawed sperm) were similar to those reported by others: $11 \%$ vs $91 \%$ (dog sperm, Alhaider \& Watson 2009), 3.1\% vs $66.7 \%$ (dog sperm, https://raf.bioscientifica.com

https://doi.org/10.1530/RAF-20-0022 (c) 2020 The authors Published by Bioscientifica Ltd

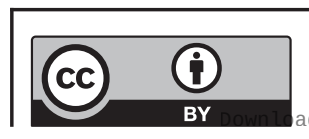

This work is licensed under a Creative Commons Attribution 4.0 International License. 
Ortega-Morales et al. 2019), and 11\% vs 55.1\% (pig sperm, Orozco et al. 2016). In addition, we measured that shift to compare the effect of MLT on plasma membrane fluidity.

We hypothesized that MLT and the cooling of spermatozoa to $-5^{\circ} \mathrm{C}$ before freezing favors sperm plasma membrane reorganization after the lipid phase transition takes place, thus avoiding an excessive increase in membrane fluidity. Our results on membrane fluidity support our hypothesis that high doses (0.002 and 0.0035 $\mathrm{mol} / \mathrm{L}$ ) of MLT significantly reduce the percentage of sperm with hyper-fluid membranes after freeze-thawing. However, similar results were obtained in dog sperm by the mere effect of pre-freeze cooling (Ortega-Morales et al. 2019). We argue that because the difference in the percentage of hyper-fluid membranes due to MLT is larger than that of cooling to $-5^{\circ} \mathrm{C}$ alone, there is an additive effect of MLT and cooling.

The protective role of MLT in sperm preservation is based on its antioxidant and anti-apoptotic properties that may either improve or maintain sperm quality (Reiter et al. 2007). There is a lack of information regarding the most appropriate doses of MLT for dog sperm cryopreservation. Varesi et al. (2014) found no differences in dog sperm cryosurvival (motility, acrosome integrity) when $0.001 \mathrm{~mol} / \mathrm{L}$ of MLT was added to the freezing extender. In ram spermatozoa, the sperm motility, DNA integrity, intracellular concentration of ATP, and fertilization rate after freeze-thawing were higher in the sperm supplemented with $0.001 \mathrm{~mol} / \mathrm{L}$ of MLT than with smaller or larger doses (Succu et al. 2011). In bulls, 0.002 and $0.003 \mathrm{~mol} / \mathrm{L}$ of MLT improved sperm cryosurvival in terms of the sperm motility, viability, plasma membrane integrity, normal spermatozoa, superoxide dismutase, and catalase activity (Ashrafi et al. 2013). In buffalo, the sperm motility, plasma membrane integrity, acrosome integrity, and conception rate after freeze-thawing were higher in the sperm supplemented with 0.0001 and $0.00025 \mathrm{~mol} / \mathrm{L}$ of MLT than in the non-supplemented sperm (El-Raey et al. 2015). In horses, the plasma membrane integrity, acrosome integrity, and high mitochondrial activity improved in the frozen-thawed sperm supplemented with $0.001 \mathrm{~mol} / \mathrm{L}$ of MLT (Lanconi et al. 2015). In humans, the motility, viability, and reduction of intracellular concentration of ROS were higher in the frozen-thawed sperm supplemented with $0.00001 \mathrm{~mol} / \mathrm{L}$ of MLT than in those supplemented with smaller or larger doses (Karimfar et al. 2015). Therefore, MLT seems to be effective in a dose of species fashion. Due to this, it may be interesting to test higher $(>0.0035 \mathrm{~mol} / \mathrm{L})$ doses of MLT on dog sperm cryosurvival.
MLT in high doses may reduce the potential of sperm fertilizing after cryopreservation. The sperm motility and viability are reduced due to ROS production being excessively neutralized and oxidative phosphorylation inhibited (Souza et al. 2016).

In conclusion, 0.002 and $0.0035 \mathrm{~mol} / \mathrm{L}$ of MLT was better than the other concentrations of MLT in terms of the quality of post-thawed dog spermatozoa.

\section{Declaration of interest}

The authors declare that there is no conflict of interest that could be perceived as prejudicing the impartiality of the research reported.

\section{Funding}

This work was partially supported by Universidad Nacional Autonoma de Mexico: PAPIIT-IA204917, IN220419; PIAPI-1615/1649/1810.

\section{Author contribution statement}

J A M-R, F J C, and R M-D-A carried out semen collection, freeze-thawing experiments, collected data and drafted the paper. A A R and A M designed and supervised the work, analyzed data, drafted and corrected the paper.

\section{References}

Alcantar-Rodriguez A \& Medrano A 2017 The effect of cooling to different subzero temperatures on dog sperm cryosurvival. Reproduction in Domestic Animals 52 422-428. (https://doi. org/10.1111/rda.12924)

Alhaider AK \& Watson PF 2009 Cryopreservation of dog semen: the effects of Equex STM paste on plasma membrane fluidity and the control of intracellular free calcium. Animal Reproduction Science 110 147-161. (https://doi.org/10.1016/j.anireprosci.2008.01.011)

Ashrafi I, Kohram H \& Ardabili FF 2013 Antioxidative effects of melatonin on kinetics, microscopic and oxidative parameters of cryopreserved bull spermatozoa. Animal Reproduction Science 139 25-30. (https://doi.org/10.1016/j.anireprosci.2013.03.016)

Balasubramanian SK, Wolkers WF \& Bischof JC 2009 Membrane hydration correlates to cellular biophysics during freezing in mammalian cells. Biochimica et Biophysica Acta 1788 945-953. (https://doi.org/10.1016/j.bbamem.2009.02.009)

Barth AD \& Oko RJ 1989 Abnormal Morphology of Bovine Spermatozoa. Ames, IA, USA: Iowa State University Press.

Cano-Suarez P, Gonzalez F, Soto R \& Medrano A 2013 The effect of melatonin on ram sperm quality during refrigeration at $5^{\circ} \mathrm{C}$ for $48 \mathrm{~h}$. Reproduction in Domestic Animals 48 (Supplement 1) 75.

Contreras-Mendez LA \& Medrano A 2016 A comparative study of two cooling protocols on stallion sperm cryosurvival. Andrologia $\mathbf{4 8}$ 558-563. (https://doi.org/10.1111/and.12479)

Crowe JH, Hoekstra FA, Crowe LM, Anchordoguy TJ \& Drobnis E 1989 Lipid phase transitions measured in intact cells with Fourier transform infrared spectroscopy. Cryobiology 26 76-84. (https://doi.org/10.1016/0011-2240(89)90035-7)

El-Raey M, Badr M, Assi M \& Rawash Z 2015 Effect of melatonin on buffalo bull sperm freezability, ultrastructure changes and fertilizing potentials. ASSIUT Veterinary Medical Journal 61 201-208.

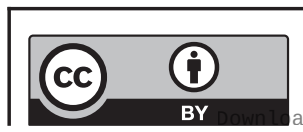

This work is licensed under a Creative Commons Attribution 4.0 International License. 
Garner DL \& Johnson LA 1995 Viability assessment of mammalian sperm using SYBR14 and propidium iodide. Biology of Reproduction $\mathbf{5 3}$ 276-284. (https://doi.org/10.1095/biolreprod53.2.276)

Garzon-Perez C, Flores HF \& Medrano A 2010 A simple osmotic stress test to predict boar sperm cryosurvival. Cryo Letters $\mathbf{3 1}$ 438-444.

González-Arto M, Vicente-Carrillo A, Martínez-Pastor F, Fernández-Alegre E, Roca J, Miró J, Rigau T, RodríguezGil JE, Pérez-Pé R, Muiño-Blanco Tet al. 2016 Melatonin receptors $\mathrm{MT}_{1}$ and $\mathrm{MT}_{2}$ are expressed in spermatozoa from several seasonal and nonseasonal breeder species. Theriogenology $\mathbf{8 6}$ 1958-1968. (https://doi.org/10.1016/j. theriogenology.2016.06.016)

Green CE \& Watson PF 2001 Comparison of the capacitation-like state of cooled boar spermatozoa with true capacitation. Reproduction 122 889-898. (https://doi.org/10.1530/rep.0.1220889)

Harrison RAP, Ashworth PJC \& Miller NGA 1996 Bicarbonate/C02, an effector of capacitation, induces a rapid and reversible change in the lipid architecture of boar sperm plasma membranes. Molecular Reproduction and Development 45 378-391. (doi:10.1002/(SICI)10982795(199611)45:3<378::AID-MRD16>3.0.CO;2-V)

Hazel JR 1995 Thermal adaptation in biological membranes: is homeoviscous adaptation the explanation? Annual Review of Physiology 57 19-42. (https://doi.org/10.1146/annurev. ph.57.030195.000315)

Holt WV 2000 Fundamental aspects of sperm cryobiology: the importance of species and individual differences. Theriogenology $\mathbf{5 3}$ 47-58. (https://doi.org/10.1016/s0093-691x(99)00239-3)

Karimfar MH, Niazvand F, Haghani K, Ghafourian S, Shirazi R \& Bakhtiyari S 2015 The protective effects of melatonin against cryopreservation-induced oxidative stress in human sperm. International Journal of Immunopathology and Pharmacology 28 69-76. (https://doi.org/10.1177/0394632015572080)

Lanconi R, Celeghini ECC, Bianchi-Alves MR, Santos GC, FlorezRodriguez SA, Leite T \& Arruda R 2015 Use of melatonin and ferulic acid as promoters of cryopreserved equine sperm. Animal Reproduction 12559.

Lopez A, Garcia JA, Escames G, Venegas C, Ortiz F, Lopez LC \& Acuna-Castroviejo D 2009 Melatonin protects the mitochondria from oxidative damage reducing oxygen consumption, membrane potential, and superoxide anion production. Journal of Pineal Research 46 188-198. (https://doi.org/10.1111/j.1600-079X.2008.00647.x)

Martinez-Hernandez DA, Rafael-Duran M, AlcantarRodriguez A, Gutierrez-Perez O \& Medrano A 2018 The effect of melatonin as antioxidant for the cryopreservation of boar spermatozoa. Cryobiology 85 184-185. (https://doi.org/10.1016/j. cryobiol.2018.10.243)
Medrano A, Holt WV \& Watson PF 2009 Controlled freezing studies on boar sperm cryopreservation. Andrologia 41 246-250. (https://doi. org/10.1111/j.1439-0272.2009.00927.x)

Medrano A, Contreras CB, Herrera F \& Alcantar-Rodriguez A 2017 Melatonin as an antioxidant preserving sperm from domestic animals. Asian Pacific Journal of Reproduction 6 241-246. (https://doi. org/10.4103/2305-0500.217317)

Moazzami M, Medrano A, Gonzalez F, Cabrera F, Batista M \& Gracia A 2014 Effect of melatonin on buck semen quality during refrigeration at $5^{\circ} \mathrm{C}$ for $48 \mathrm{~h}$. Reproduction in Domestic Animals 49 (Supplement 4) 123.

Orozco J, Alcantar-Rodriguez A, Gutierrez-Perez 0 \& Medrano A 2016 Merocyanine detects changes in pig sperm plasma membrane fluidity in different steps of conservation. In Proceedings of the 18th International Congress on Animal Reproduction, Tours, France, pp. 151-152.

Ortega-Morales LD, Alcantar-Rodriguez A, Espejel MC \& Medrano A 2019 The effect of non-traditional cooling on dog sperm cryosurvival and capability to suffer the acrosome reaction. Austral Journal of Veterinary Sciences 51 73-82. (https://doi. org/10.4067/S0719-81322019000200073)

Peña A \& Linde Forsberg C 2000 Effects of Equex, one-or two-step dilution, and two freezing and thawing rates on post-thaw survival of dog spermatozoa. Theriogenology $\mathbf{5 4}$ 859-875. (https://doi. org/10.1016/S0093-691X(00)00397-6)

Reiter RJ, Tan DX, Terron MP, Flores LJ \& Czarnocki Z 2007 Melatonin and its metabolites: new findings regarding their production and their radical scavenging actions. Acta Biochimica Polonica 54 1-9. (https://doi.org/10.18388/abp.2007_3264)

Snedecor GW \& Cochran WG 1989 Statistical Methods, 8th ed. Ames, USA: Iowa State University Press.

Souza WL, Moraes EA, Costa J, Sousa PH, Lopes JES, Oliveira RP \& Toniolli R 2016 Effect of different concentrations of melatonin to ram spermatozoa on oxidative stress after cryopreservation. Pesquisa Veterinaria Brasileira 36 657-664.

Succu S, Berlinguer F, Pasciu V, Satta V, Leoni GG \& Naitana S 2011 Melatonin protects ram spermatozoa from cryopreservation injuries in a dose dependent manner. Journal of Pineal Research $\mathbf{5 0}$ 310-318. (https://doi.org/10.1111/j.1600-079X.2010.00843.x)

Varesi S, Vernocchi V, Morselli MG \& Luvoni GC 2014 DNA integrity of fresh and frozen canine epididymal spermatozoa. Reproductive Biology 14 257-261. (https://doi.org/10.1016/j. repbio.2014.07.001)

Watson PF 1995 Recent developments and concepts in the cryopreservation of spermatozoa and the assessment of their postthawing function. Reproduction, Fertility, and Development 7 871-891. (https://doi.org/10.1071/rd9950871)

Received in final form 16 September 2020

Accepted 22 September 2020

Accepted Manuscript published online 22 September 2020 https://raf.bioscientifica.com https://doi.org/10.1530/RAF-20-0022 (c) 2020 The authors Published by Bioscientifica Ltd

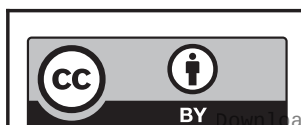

This work is licensed under a Creative Commons Attribution 4.0 International License. 